\title{
The Impact of Knowledge Management on Service Quality of News Researcher in XYZ Television
}

\author{
Jhoni Marcos ${ }^{1}$, Mulya Riawan Mashudi ${ }^{2}$ \\ ${ }^{1}$ Department of Information Technology, Swiss German University, Tangerang 15143, Indonesia
}

\author{
Article Information \\ Received: \\ Accepted: \\ Published: \\ DOI: $10.33555 /$ ejaict.v... \\ Corresponding Author: \\ Jhoni Marcos \\ Email: \\ jhoni_marcos@yahoo.com \\ ISSN 2355-1771
}

\begin{abstract}
The main objective of this research is to find out whether there is an impact of the implementation of knowledge management $(\mathrm{KM})$ on the service quality of the news researcher (NR) work unit in the news divisions at XYZ Television. The positive influence of $\mathrm{KM}$ is expected to improve the service quality provided to news producers as users. So that it also has a positive or increasing impact on the quality of the news produced. This type of research is applied research, with experimental research methods. According to the level of exploration, this study uses a comparative method by comparing the results before and after the implementation of KM. According to the type of data, this study uses qualitative data. For this reason, a survey was conducted using a questionnaire before and after the implementation of KM to 28 news producers as respondents. These respondents were the total population of users who are received NR services. The rating scale used is a Likert scale. The statistical test used for this study used paired sample ttest using IBM SPSS 25, which tests the hypothesis whether there is a significant impact of KM implementation. This study has proven that the application of KM can improve the service quality of NR. This increase is indicated by the significance value of the service before and after the implementation of KM. So that this research is expected to contribute to the improvement of service quality in each work unit of news researchers in television media in Indonesia, especially in the news division.
\end{abstract}

Keywords: Knowledge Management, Service Quality, News Researcher 


\section{Introduction}

$\mathrm{XYZ}$ Television is general entertainment channel. Where all types of programs are provided, there are entertainment, information, sports and news. Not like a news channel whose overall program composition is filled with news content only. In XYZ Television, News is one of the programs that contributes about $30 \%$ of the total daily broadcast. But News is an important part of a television media company, since it can be a bargaining position in society and government. In news, speed of reporting is a must, where news must be fast, actual and complete, packed with a grace period that is narrow enough to immediately be presented to viewers.

In XYZ news division, a News Researcher (NR) greatly contributes to a series of news program production. The NR unit provides additional important information and knowledge to the news producer (user) who will create a news script. The material from NR unit is the basis for information or reinforces the news information that will be presented. The service quality of NR will affect the output given to the user.

The author works at this company as the Head of the News Facilities and Operation Department in charge of the News Researcher (NR) work unit. So, the author is responsible for improving the service quality in this work unit. Discussions through FGDs and working meetings are often held to discuss the SQ of this NR. The author tries to identify the problems. Using root-cause analysis approach, some of the problems identified can be described in the Fishbone Diagram in figure 1.1.

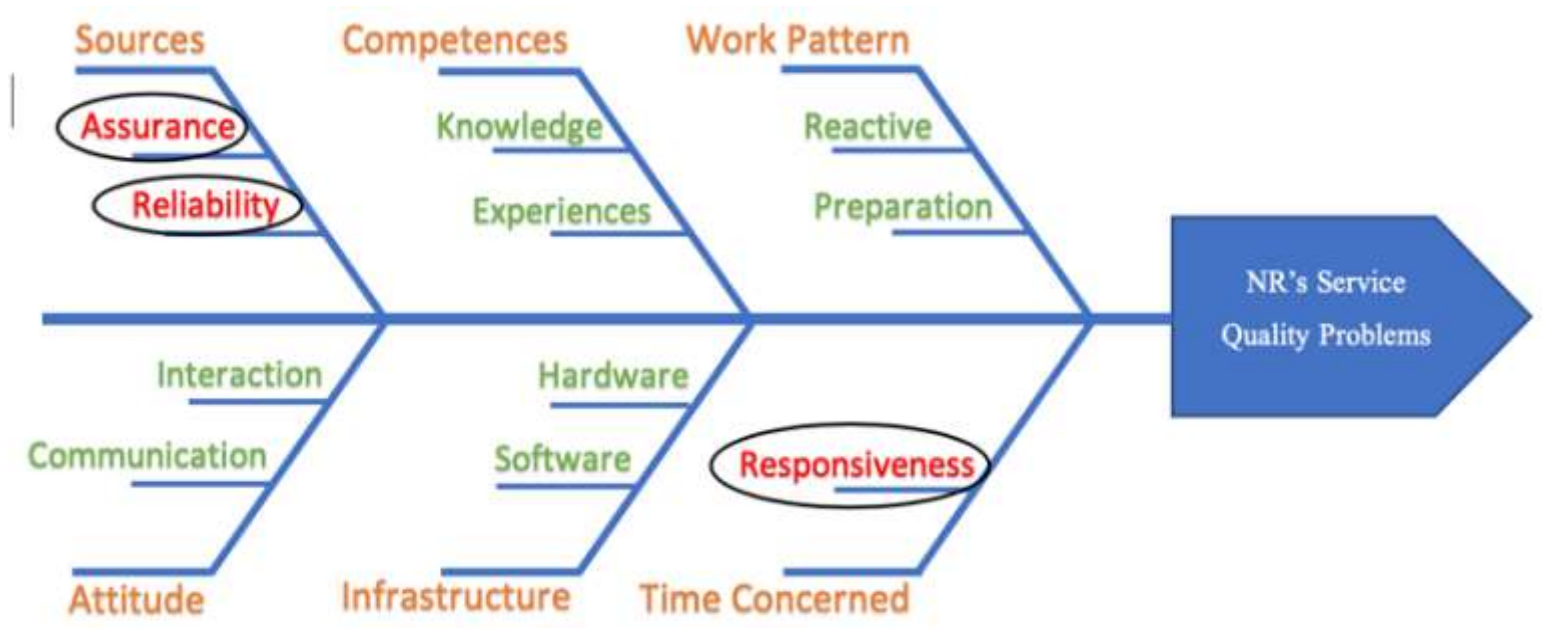

Figure 1. Root-Cause Analysis by Fishbone Diagram of NR's Service Quality Problems

Figure 1 [1] shows that there are three main problems circled in the figure. These three main problems are considered to be improved immediately in order to improve the SQ of NR, which is guaranteed data availability, accuracy of data/ information and validity sources, and speed of data delivery. These three main problems also often appear in evaluation meetings in the News Division. Based on the consideration of time that is also limited, this research is only focused on the three main problems mentioned. These problems are classified as problems with Service Quality (SQ).

Broadly the dimensions of service quality accepted are tangibility, empathy, reliability, responsiveness, and assurance [2]. Based on the identification of root-cause analysis problems as depicted in the fishbone diagram in figure 1.1, the three main problems to be investigated are, where the guarantee of data availability can be classified in the assurance dimension, accuracy of data/ information and validity sources can be classified in the reliability dimension, and the speed of data delivery included in responsiveness dimension category. 
The currently working patterns of the NR unit in this XYZ Television is reactive rather than anticipatory. With this currently work pattern, it takes more time to deliver data or information to News Producers (user), and frequently also problems with the availability and accuracy of data or information caused by limited deadlines. Users always request data or information to the NR unit mostly only an hour before the on-air. While one news researcher with another has different experiences, maturity and knowledge. Certainly, one another will provide a different level of service.

Knowledge Management (KM) is a business concept that has developed rapidly, especially since the 2000s. In general $\mathrm{KM}$ is a process that coordinates the use of information, knowledge and experience. Knowledge is the result of information that has been processed. Where there are values, insights, experiences, and contextual information that will help someone in evaluating and combining new experiences, so as to create a new knowledge [3]. Knowledge would be very useful for stakeholders who are able to access, through a collaborative environment. It would be useful for decisions making, fast learning, data analysis, and others.

For this reason, the author thinks that KM can be applied to solve three main problems in SQ in this NR unit. For this reason, this study was conducted to prove the author's hypothesis. Author in this paper will focus to make research about the three main problems that occurred in NR unit. As mentioned before, the Service Quality (SQ) discussed is limited to the speed of delivery time (responsiveness), data availability (assurance) and the accuracy (reliability) of the data/ information that provided to the user. This paper discusses empirically whether and how KM can be used to improve SQ.

\section{Theoretical Background}

This section defines and discusses the nature of service quality and knowledge management in general based on existing theories. Then explained more about the lifecycle of knowledge management and the dimensions that exist in service quality.

\subsection{Service Quality}

One measure to determine whether a company/ organization has a good service quality is whether or not the target set by the company/ organization has been achieved. The achievement of company/ organizational goals is strongly supported by the quality of existing human resources. If the quality of its human resources is good, it is expected that the quality of the company/ organization will be good too. However, to get good service quality it is necessary to manage quality effectively.

The dimensions of service quality (SERVQUAL) that are widely accepted are tangibility, empathy, reliability, responsiveness, and assurance [2]. Such measurements are known as service quality (SERVQUAL) models. In the SERVQUAL model, service quality is defined as "global judgment or attitude regarding the superiority of a service" [4], while the definition of service quality which is often referred to as service quality [5] is how far the difference is between reality and customer expectations for the service they receive or receive. Hope is the desire of customers from the services that may be provided by the company. 


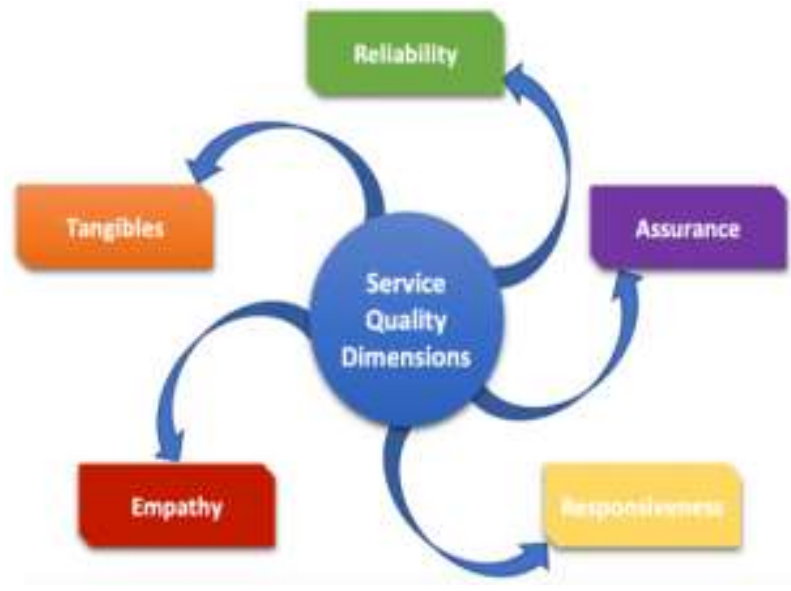

Figure 2.1.

Figure 2. Service Quality Dimensions [6]

The SERVQUAL model has a service quality dimension based on a multi-item scale, which is then designed to measure customer expectations and perceptions, as well as the gaps that exist between the two in the service quality dimension. Initially, Parasuraman et al. (1985) identified 10 main dimensions, with 22 variables related to services, then all dimensions and variables were analyzed using factor analysis. The results of the analysis found that apparently several criteria could be used to assess service quality. This criterion includes ten potential dimensions that complement each other. The ten dimensions are physical evidence, credibility, reliability, responsiveness, competence, communication, security, courtesy, understanding, and access. Then in subsequent studies, Parasuraman et al in 1988 perfected the dimensions and then reprocessed them so that they were finally simplified into 5 dimensions, namely:

1. Direct evidence (tangibles); include equipment, physical facilities, communication facilities, and employees.

2. Reliability (reliability); that is, the ability to provide the promised service with accuracy, integrity and satisfaction.

3. Responsiveness (responsiveness); that is, the desire of service providers to help customers and provide services responsively and quickly.

4. Guarantee (assurance); including ability, service availability, knowledge, courtesy, and staff trust, free from risks and danger.

5. Empathy (empathy); including good communication, easy relationships, personal attention, and understanding customer needs.

The service quality dimension for NR, which is the main concern in evaluation discussions, is reliability, assurance and responsiveness. Because these three dimensions are highly expected to increase in the services provided by NR to their users. So, service quality dimensions in this research will be focused and limited to three dimensions, namely reliability, assurance and responsiveness. The other dimensions, namely empathy and tangible, do not match the service character of NR. These two dimensions are more appropriate in relation to other services, such as service by receptionists in hotels.

In the context of management and service quality evaluation, the formulation of the problem and the determination of management decisions to be taken or determined is the answer to the question; What is at issue? Where is the service quality in question? When do we fix this service quality problem? Why do we need to fix? Who should do it? How to implement and manage the service quality?

\subsection{Knowledge Management}

KM refers to identifying and utilizing collective knowledge in an organization to help competing organizations [7]. Typically, KM consists of a knowledge process that is supported by infrastructure, so that management capabilities and activities can support and enhance the knowledge process. Knowledge 
management has been increasingly seen as one of the most important practices for organizations to improve its efficiency, effectiveness and long-term competitive advantage [8].

The purpose of knowledge management is not to manage all knowledge but only the most important knowledge needed by the organization. KM is needed to ensure that people will have the knowledge they need, where they need it, and when they need it. That is, the right knowledge, in the right place, at the right time [9]. KM is not about creating a new department, but how to make a small change to the workings of an organization. In general, $\mathrm{KM}$ aims to create a knowledge environment that requires changes in organizational values and culture, by changing work behavior and patterns, and giving workers easy access to each other to relevant information resources [9].

Effective knowledge management plays an important role in the emergence of a knowledge-based economy [10]. This effectiveness has been described as one important element for organizations to ensure sustainable strategic competitive advantage. Knowledge management is expected to be a key driver of organizational quality and an important tool for organizational survival, competitiveness and profitability. Therefore, to create, manage, share and use knowledge effectively is very important for the organization.

The main goal of Knowledge Management are as follows:

- To improve the quality of management decision making in an organization, by ensuring that throughout its life cycle reliable and safe data / information can always be available.

- Capture, develop, share and use organizational knowledge.

- To be able to increase efficiency by reducing the need for rediscovering knowledge.

Such knowledge processes such as knowledge creation, sharing, acquisition, transfer and application [11]. The literature on KM includes several categories of KM practices and activities. It can be divided into knowledge creation, incorporation and dissemination. Similar to this view, this paper proposes that the KM lifecycle can be divided into four main types [12]:

1. Knowledge Acquisition,

2. Knowledge Codification,

3. Knowledge Storage,

4. Knowledge Sharing.

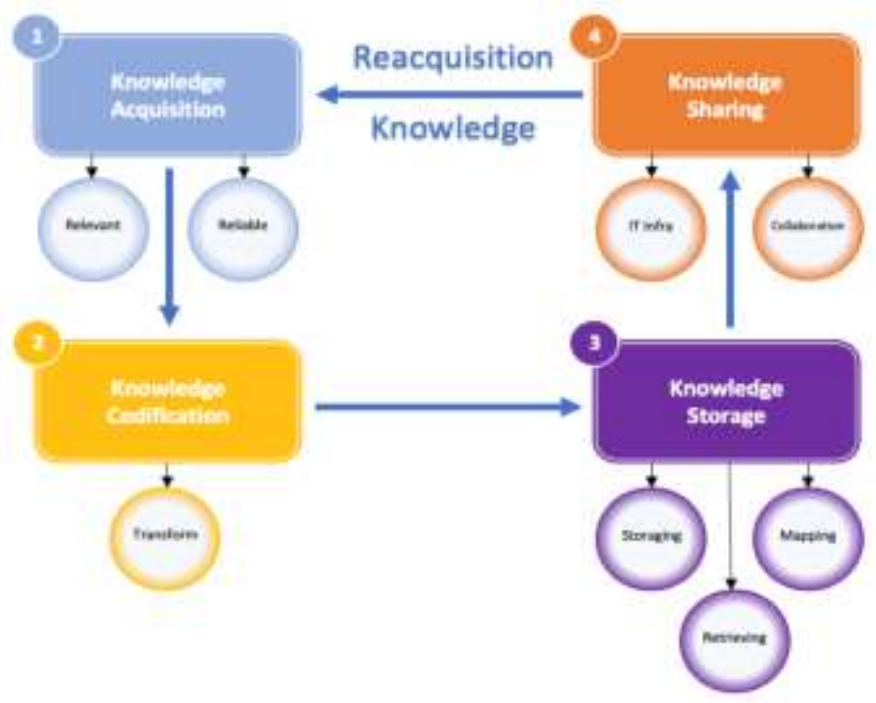

Figure 3. Knowledge Management Lifecycle Diagram [13]

Although these types, to some extent, are interrelated and overlapping, they can be distinguished individually because of their different focus. Each of the four KM processes is briefly explained below. 
Knowledge acquisition stands for organizational practice aimed at gathering information from extraorganizational sources [14]. External networks and collaborative arrangements are important sources of knowledge for all types of organizations. Users form a very important group from which knowledge must be obtained if the organization is to succeed. For example, user feedback systems, data mining, business intelligence and collaboration with partners and research institutions are characteristics of very advanced knowledge acquisition practices.

\subsubsection{Knowledge Codification}

Codification and storage are very important for reactivating and integrating knowledge. The codification of knowledge itself consists of a series of activities needed to compile tacit knowledge into explicit form, to store documented knowledge and to provide the latest documented knowledge to others in the organization [15]. This is based on the availability of technology systems, platforms and tools, as well as the right information and communication. Then related employee skills and motivation are used to make employee knowledge explicit and to compile and store it, so that it can later be used in systems and documents.

\subsubsection{Knowledge Storage}

Knowledge storage refers to activities related to managing knowledge resources. It is very important that this knowledge must be stored properly. Ideally, this needs to be equipped with information technology tools and platforms that will facilitate codification so that it is effective in storing explicit knowledge in databases, making it easier to find and transfer this knowledge.

\subsubsection{Knowledge Sharing}

Sharing knowledge is the key to managing knowledge, whether it is tacit or not. For those with tacit knowledge, organizations must encourage face-to-face communication and the creation of shared learning experiences, and build a culture of knowledge sharing [16]. Knowledge sharing activities include informal communication, brainstorming sessions, guidance and coaching. In this paper, the context of sharing is also through facilities, namely through a centralized database. So, everyone works in a collaborative way. To be able to share together all the knowledge gained and possessed.

\subsection{Hypothesis}

The hypothesis for this research has been defined as follows:

Ho: There is no difference in the mean value of service quality (assurance, reliability and responsiveness) before and after Knowledge Management is applied.

Ha: There are differences in the mean value of service quality (assurance, reliability and responsiveness) before and after Knowledge Management is applied.

\section{Research Methods}

In this section, the implementation of the proposed model and the evaluation of the model will be discussed. This research is using applied research with experimental that compare two situation and measure it based on quantitative research.

The impact of KM on service quality was then empirically tested by analyzing a survey of 28 respondents, collected from the all of news producers in XYZ Television as users. 28 respondents are not a sampling, but the total population of users who get services from NR.

This survey was given to all these users before the KM implementation and after the KM implementation. So that later we can see the difference in the pre-post scores. 
Data collection technique in this research used a questionnaire with a Likert scale. Responses to the items in the questionnaire will be separated in four alternative answers, namely 1 (Strongly Disagree), 2 (Disagree), 3 (Neutral), 4 (Agree), and 5 (Strongly Agree). Service quality questionnaires were used before and after implemented of knowledge management to all users.

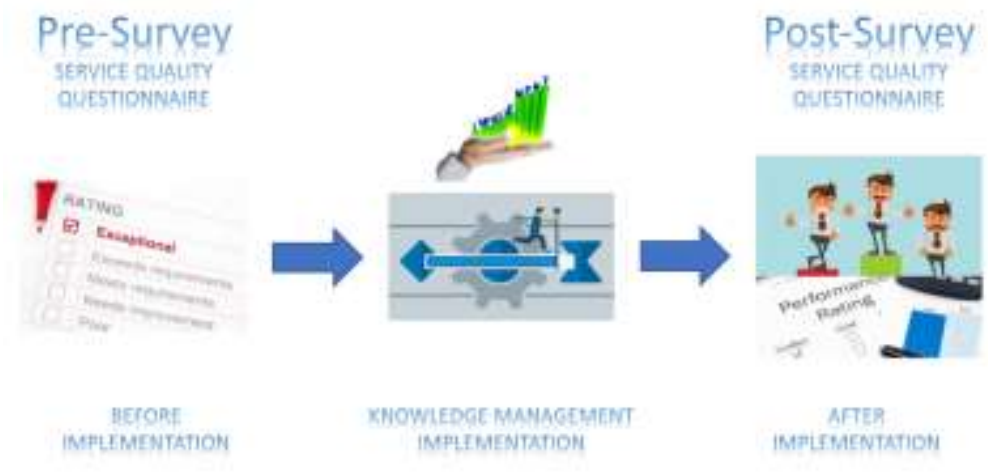

Figure 4. The pre-post survey was conducted to 28 respondents

The basic concept of a paired sample t-test is as follows:

- Paired sample t-tests are used for whether there are differences in the average of two paired samples.

- The two samples in question are the same sample but have two data.

- Paired sample t-test is a part of parametric statistics, therefore as per the rules in parametric statistics, research data must be normally distributed.

Service quality is one of the most widely researched topics in the organizational behavior literature and has been actively studied. Prerequisites for high quality service have been widely studied. However, KM issues have not been included among the many service quality factors to be examined. In general, it seems that the $\mathrm{KM}$ literature rarely discusses the impact KM can have on "soft" performance issues, such as service quality. KM processes constitute such contextual features of the work environment, which can enrich the job and increase service quality. The KM process in an organization can help workers in a knowledge intensive environment so as to build mutual understanding to get value from knowledge. More specifically, knowledge acquisition increases service quality because it involves access to new knowledge collections that can improve efficiency in carrying out one's duties. Codification of knowledge also helps people find the data or information they need faster and more effectively in carrying out their tasks.

Sharing knowledge can meet the social needs of individuals involved in it. They will bind to each other, and become more confident. Knowledge retention increases employee recognition and appreciation, because it is based on the recognition of the value of individual expert knowledge. In short, the authors suggest that employees will be more satisfied with their work insofar as they experience the KM process in their work environment. The approach of solution to solve the problems is depicted in Figure 3.1. This figure illustrates how the relationship of independent variables can have an impact on the dependent variable with the accompanying dimensions.

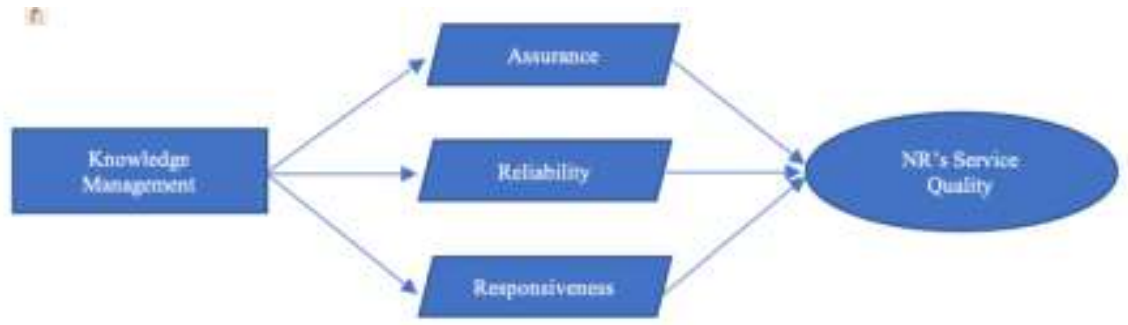

Figure 5. Solution approach to improving SQ of NR 


\section{Results and Discussions}

The results of research obtained through the stages of the method previously described. Where here also further explained the need for support in conducting research.

\subsection{Implementation of Knowledge Management}

The implementation of a new work pattern with the KM concept began in the middle of May 2019. Prior to implementation, the author first conducted socialization both internally and externally to the department. In the internal department, the author conducts socialization and knowledge sharing about KM to NR. In the external department, the writer does it to the news producer as the user. The work patterns adopted in adopting $\mathrm{KM}$ are illustrated as in the figure 4.1.

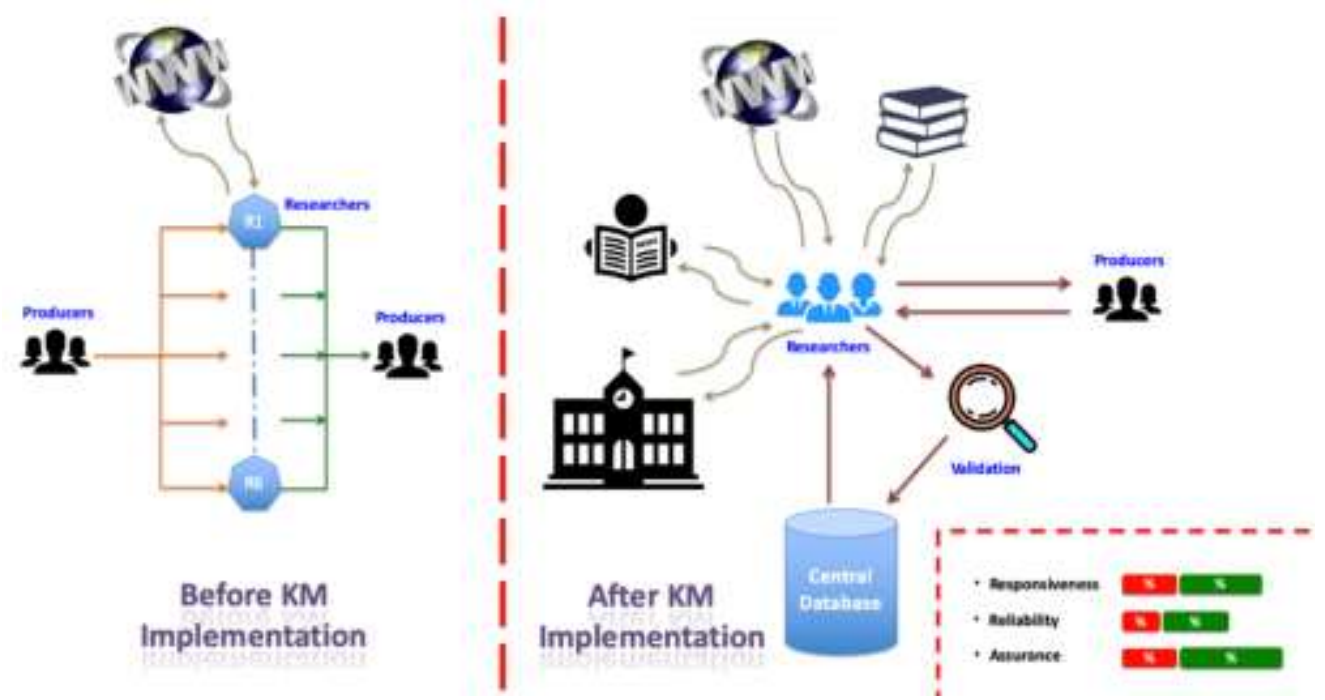

Figure 6. Expectation of KM implementation workflow

Figure 4.1 illustrates two different work patterns, between before and after the implementation of KM. In the left side of picture, it can be explained that just before KM was applied, the pattern of action was reactive. NR works only when there is a request for data / information needed by the user. Where data requests are usually approximately one hour before the news is broadcast. So that NR has only a little time to fulfill several requests at the same time almost simultaneously from several news producers. NR can only search for data / information requested from one source, namely the internet. Then with all its limitations, NR provides its services as much as possible.

In contrast to the right side of picture, work pattern when KM has been applied. Where NR will work more anticipatory, not only when there is a request from the user, but has begun to search for data / information that might later be needed from the user before being asked. Sources can be from the internet, books, papers, from institutions that work with XYZ Television, such as BPS (Statistics Indonesia), ANRI (National Archives of the Republic of Indonesia, and other authorized institutions.

\subsection{The Operationalization of The KM Variable}

Operationalization for the independent variable KM by applying the cycle that is in the KM concept, which starts with Knowledge Acquisition, then Knowledge Codification, then Knowledge Storage and finally Knowledge Sharing.

- Knowledge acquisition; in the application in NR, we collect data/ information from various sources that can be trusted and accounted for. These sources include books, journals, papers, seminars, related institutions, resource persons, and the internet.

- Knowledge codification; in the application in NR, data/ information in the form of verbal or audio video is codified first. So that data/ information changes in written form that can be stored in a database.

- Knowledge storage; in the application in NR, data/ information that has been collected, is stored in a structured table in a centralized database. 
- Knowledge sharing; after data/ information is stored in a database, it can be accessed together or collaborated by news researchers. So, when the user needs the data/ information later, all that remains is to be pulled from the database and processed into a new knowledge before it is given to news producers as its users.

\subsection{The Operationalization of The $S Q$ Variable}

Operationalization for the dependent variable SQ is by testing the three dimensions previously discussed, namely the dimensions of Reliability, Assurance and Responsiveness.

- Dimensions of reliability; contains problems that must be solved in it, namely the need for data accuracy, valid or accountable sources, consistency, and complete.

- Dimensions of assurance; contains problems that must be solved in it, namely guarantees of good cooperation between users and service providers, guarantees of knowledge of service providers and guarantees of meeting the needs of users of the services provided.

- Dimensions of responsiveness; contains problems that must be solved in it, namely the readiness in providing services with responsiveness at all times, and can provide responses to the needs of the service quickly.

\subsection{Statistical Testing}

After obtaining the complete questionnaire data from 28 respondents, the authors conducted a statistical test of the data using the IBM SPSS 25 application. The results are as follows in the table 4.1. This test compares the significance value between before and after the implementation of KM to SQ.

Table 1. Paired Samples Statistics

\begin{tabular}{ccc|c|c|c} 
& & & & & Std. Error \\
Mean & $\mathrm{N}$ & Std. Deviation & Mean \\
\hline \multirow{2}{*}{ Pair 1 } & Before & 24.96 & 28 & 4.342 & .821 \\
\cline { 2 - 6 } & After & 39.32 & 28 & 4.769 & .901 \\
\hline
\end{tabular}

From the table 4.1 it can be analyzed that this research uses a sample of $n 1=28$ and $n 2=28$ respondent. The mean value for $\mathrm{X}=24.96$ and mean value for $\mathrm{Y}=39.32$. standard deviation $(\mathrm{Sx})=4.342$, and standard deviation $(\mathrm{Sy})=4.769$. From these results it can be seen that the average value of service quality after applying knowledge management is higher than before, which means that there was an improvement in SQ after KM was implemented.

Table 2. Paired Samples t-Test

Pair 1

Before - After

\begin{tabular}{llr}
\hline Paired Differences & \multicolumn{1}{l}{ Mean } & -14.357 \\
\cline { 2 - 3 } & Std. Deviation & 3.423 \\
\cline { 2 - 3 } & Std. Error Mean & .647 \\
\cline { 2 - 3 } & & -15.685 \\
\hline
\end{tabular}




\begin{tabular}{lrr}
\hline & $\begin{array}{l}\text { 95\% Confidence Interval } \\
\text { of the Difference }\end{array}$ & Upper \\
\hline t & & -13.030 \\
\hline df & & -22.192 \\
\hline Sig. (2-tailed) & .000 \\
\hline
\end{tabular}

Tests using a two-tailed test with a significance level $\mathrm{a}=5 \%$. The level of significance in this case means the risk of making a wrong decision to reject the correct hypothesis is as much as $5 \%$.

From the paired sample test table, the results are obtained:

- $\mathrm{t}$ value was obtained from the paired sample test table $=-22.192$

- $\mathrm{t}$ table value of $\mathrm{a}=5 \% / 2=2.5 \%$ (two-tailed test) with degrees of freedom (df) $\mathrm{n}-1$ is $28-1=27$. With 2-sided testing (significance $=0.025$ ) the results obtained for $\mathrm{t}$ table amounted to 2,052.

- Test Criteria:

$0 \quad$ Ho is accepted if $-\mathrm{t}_{\text {table }} \leq \mathrm{t}$ count $\leq \mathrm{t}_{\text {table }}$

0 Ho is rejected if $-t_{\text {count }}<-t_{\text {table }}$ or $t_{\text {count }}>t_{\text {table }}$

- Based on probability:

- Ho is accepted if $\mathrm{P}_{\text {value }}>0.05$

- Ho is rejected if $\mathrm{P}_{\text {value }}<0.05$

- The results of the comparison of $t_{\text {table }}$ and $t_{\text {count }}$ are:

$\circ$ Value of $-t_{\text {count }}<-t_{\text {table }}(-22.192<-2.052)$ and $P_{\text {value }}(0.000<0.05)$ then Ho is rejected.

$\circ$ This matter means there are differences in the average value of service quality (assurance, reliability and responsiveness) before and after Knowledge Management is applied.

$\circ$ Value of $t_{\text {count }}$ negative shows that the average value of service quality before applying knowledge management is lower than afterwards.

Based on the statistical explanation above it can be seen that the application of KM can improve the quality of service in NR. This is reinforced by the theory that KM aims to create a knowledge environment that requires changes in organizational values and culture, by changing work behavior and patterns, and giving workers easy access to each other to relevant information resources [9]. Service issues related to assurance, reliability and responsiveness that can still be corrected through the application of KM.

As for the KM implementation, there are significant changes in each dimension with the highest order, namely the responsiveness dimension, then the assurance dimension and finally the reliability dimension.

\subsection{The Results of Gap Analysis}

After the application of KM in SQ, the results can be seen based on the gap analysis previously discussed in chapter 3. Here we can see the different situations from before and after KM was applied.

Current situation:

- Guaranteed availability of data / information needed.

- More choices of data / information sources to meet the requested needs.

- Has data / information source validity.

- Response time given by NR is much faster in conveying data / information provided to users.

- A lot of time is spent searching for data / information needed before the request arrives.

Ideal situation: 
- Changes in workflow from reactive to anticipatory can be realized.

- Guaranteed availability of data from several valid and integrated sources of choice, by presenting it more quickly and responsively.

Based on the survey conducted using a questionnaire, it can be concluded that the pre-survey and postsurvey are as follows:

- In the pre-survey, the highest score that can be generated from each dimension can only reach a value of 4 . The dimension that has the highest total score of 4 is assurance $38.1 \%$.

- In the post-survey, the highest score that can be generated from each dimension can reach a value of 5. Dimensions which have the highest total score of 5 are responsiveness of 58.9\%.

- The largest score difference is in the dimension of responsiveness, where it has a difference value of $55.3 \%$. The second rank is occupied by the reliability dimension of $25 \%$, and the last rank is occupied by the assurance dimension of $16.7 \%$.

- So, it can be concluded that with the application of KM, the most significantly increased dimension of service quality is responsiveness. This indicates, the response given by NR is much faster than before KM was implemented.

Table 3. Highest Score Average of Each Dimension Survey Results

\begin{tabular}{|c|c|c|c|}
\hline Dimension & $\begin{array}{c}\text { Highest Score } \\
\text { Average } \\
\text { Pre-Survey }\end{array}$ & $\begin{array}{c}\text { Highest Score } \\
\text { Average } \\
\text { Post-Survey }\end{array}$ & $\begin{array}{c}\text { Difference of } \\
\text { Highest Score } \\
\text { Average }\end{array}$ \\
\hline Reliability & $14.3 \%$ & $39.3 \%$ & $25 \%$ \\
\hline Assurance & $38.1 \%$ & $54.8 \%$ & $16.7 \%$ \\
\hline Responsiveness & $3.6 \%$ & $58.9 \%$ & $55.3 \%$ \\
\hline
\end{tabular}

\section{Conclusion and Recommendation}

\subsection{Conclusion}

Based on data analysis using the IBM SPSS 25 application, the results show that there is positive impact in SQ after KM is applied to NR work units on XYZ Television. The average value before is smaller than after $\mathrm{KM}$ was applied, which means that there was an improvement in SQ after KM was implemented. This explains that by applying KM, it can increase the SQ of NR. Of the three dimensions in SQ the most affected are the responsiveness dimension. Where this dimension is the most significant increase in value. The second rank is occupied by the reliability dimension, and the third rank is occupied by the assurance dimension.

This is reinforced by the results of observations and discussions (FGD) that the speed of data presentation that was previously longer, when after the application of KM becomes faster and more responsive when users need services.

The SQ in question is in the form of reliability, assurance and responsiveness. The application of KM is carried out for seven months through the cycle of knowledge acquisition, knowledge codification, knowledge storage and knowledge sharing. 
The author advises XYZ Television to continue to implement KM, because KM can indeed maintain service quality and, thereby, grow high quality service by changing workflows from reactive to anticipatory patterns. So, KM will anticipate and fill the knowledge gap between one researcher and another. KM needs to provide an average standard of quality for all news researchers in terms of expected service quality. KM approach with data centralization is expected that everyone in this unit can access data and information together. So that the time of providing data will be faster and more accurate and will certainly ensure its availability.

The same thing the authors recommend to similar companies like XYZ Television which has a news division in it. By implementing the same thing on XYZ Television, it is expected to also be able to give the same results in accordance with the evidence given by this research.

\section{References}

\section{[1] J. Marcos, "THE IMPACT OF KNOWLEDGE MANAGEMENT ON SERVICE QUALITY OF NEWS RESEARCHER IN XYZ TELEVISION,” Swiss German University, Tangerang, 2020.}

[2] A. Meesala and J. Paul, "Service quality, consumer satisfaction and loyalty in hospitals: Thinking for the future," Journal of Retailing and Consumer Services, vol. 40, pp. 261-269, Jan. 2018, doi: 10.1016/j.jretconser.2016.10.011.

[3] R. Abdullah, M. H. Selamat, U. P. Malaysia, S. Sahibudin, A. Alias, and U. T. Malaysia, “A framework for knowledge management system implementation in collaborative environment for higher learning institution," Journal of Knowledge Management Practice. Retrieved from http://www.tlainc.com/articl83.htm Abell, A., \& Oxbrow, N, 2005.

[4] A. Parasuraman, V. A. Zeithaml, and L. L. Berry, "A Conceptual Model of Service Quality and Its Implications for Future Research,” Journal of Marketing, vol. 49, pp. 41-50, Sep. 1985.

[5] A. Parasuraman, V. A. Zeithaml, and L. L. Berry, "SERVQUAL: A Multiple-Item Scale for Measuring Consumer Perceptions of Service Quality,” Journal of Retailing, vol. 64, pp. 12-40, 1988.

[6] R. Kant, D. Jaiswal, and S. Mishra, "The Investigation of Service Quality Dimensions, Customer Satisfaction and Corporate Image in Indian Public Sector Banks: An Application of Structural Equation Model(SEM),” Vision, vol. 21, no. 1, pp. 76-85, Mar. 2017, doi: 10.1177/0972262916681256.

[7] A. Kianto, M. Vanhala, and P. Heilmann, "The impact of knowledge management on job satisfaction," J of Knowledge Management, vol. 20, no. 4, pp. 621-636, Jul. 2016, doi: 10.1108/JKM-10-2015-0398.

[8] S. Sukumaran, S. S. Amalathas, C. G. K. Simon, S. S. Mustapha, I. A. T. Hashem, and A. F. Zulkifli, "A Case Study on Knowledge Management Implementation in the Banking Sector - Issues and Challenges," in 2018 Fourth International Conference on Advances in Computing, Communication \& Automation (ICACCA), Subang Jaya, Malaysia, Oct. 2018, pp. 1-6, doi: 10.1109/ICACCAF.2018.8776746.

[9] D. R. O. Shannak, “Knowledge Management Strategy Building,” European Scientific Journal, vol. 8, p. $27,2012$.

[10] F. O. Omotayo, "Knowledge Management as an important tool in Organisational Management: A Review of Literature,”p. 24, 2015.

[11] H. Lee and B. Choi, "Knowledge Management Enablers, Processes, and Organizational Performance: An Integrative View and Empirical Examination,” Journal of Management Information Systems, vol. 20, no. 1, pp. 179-228, Jul. 2003, doi: 10.1080/07421222.2003.11045756.

[12] U. M. S.D, C. Sivasubramanian, and T. N. S. Dath, "A comprehensive analysis of knowledge management in Indian manufacturing companies," Jnl of Manu Tech Mnagmnt, vol. 28, no. 4, p. JMTM-08-2016-0107, May 2017, doi: 10.1108/JMTM08-2016-0107.

[13] M. Sa, “A NEW LIFE CYCLE MODEL FOR PROCESSING OF KNOWLEDGE MANAGEMENT,” p. $10,2006$.

[14] W. M. Cohen and D. A. Levinthal, "Absorptive Capacity: A New Perspective on Learning and Innovation," Administrative Science Quarterly, vol. 31, pp. 128-152, 1990.

[15] R. Filius, J. A. de Jong, and E. C. Roelofs, "Knowledge management in the HRD office: a comparison of three cases," Journal of Workplace Learning, vol. 12, no. 7, pp. 286-295, Nov. 2000, doi: 10.1108/13665620010353360.

[16] I. Nonaka, “The Knowledge-Creating Company,” in The Economic Impact of Knowledge, Elsevier, 1998, pp. 175-187. 


\section{Acknowledgement}

Firstly, the author wishes to give thanks to Allah Subhanahuwata'ala who guards me in this research, because without Allah Subhanahuwata'ala, I couldn't complete this thesis.

Secondly, thanks to my family for the support. And the last but not least, thanks to Swiss German Univeristy and all the lecturers, especially to Dr. Ir. Moh. A. Amin Soetomo, M.Sc., Dr. Mulya Riawan Mashudi,S.T., MEM., Dr. Charles Lim, M.Sc, and MIT Study Program Head Dr. Eka Budiarto, S.T., M.Sc., who helpful in guiding me from beginning.

This paper is a conversion from my thesis which I did to complete my master's studies. Hopefully this research is useful for others, because I really feel the benefits, both for the company where I work and I personally. 